\title{
Male Engagement in Deconstructing Institutional Violence in Kenya
}

\section{Phil Erick Otieno}

Abstract As violence is a power issue, there is a need to understand the root causes and the manifestations of power relations in all spheres of life. In this regard, it is important to change norms and attitudes, as well as to influence policy and practice in both public and private institutions. This must be buttressed by appreciation of the variety of contextually explicit pathways to change. By interacting with different communities, the intersection between SGBV, HIV and AIDS become apparent. There are men ready to engage in working towards gender equality but who require a secure and non-threatening platform to facilitate non-violent reflections and deliberations on numerous gender issues pertinent to their personal lives, family, work and community. In seeking to create a violence-free society where females and males are valued equally, there is a need to interrogate the structural violence that impedes the attainment of that goal.

\section{Introduction}

This article seeks to examine institutional and structural violence in Kenya and to highlight efforts to address it. The practical interventions herein are more general and target social justice movements in Kenya. This article also endeavours to analyse the role of men in curbing sexual and gender-based violence (SGBV), including the constraints faced by different social justice movements in engaging men in gender equality initiatives.

\section{Demystifying institutionalised violence}

Violence against women and girls, from verbal harassment to physical assault, is institutionally entrenched, due to inadequate policies and mechanisms for dealing with such violence, as well as the institutional cultures and norms that legitimise it. Both are rooted in patriarchal practice and ideology, which are reflected in male-dominated authority structures. These often minimise the extent and gravity of SGBV in most institutions and overlook or ignore the sexism that exposes women and girls to abuse in the public and private spheres. While women's organisations have been challenging this institutionalised violence for many years, it is time that more men got involved as allies in the struggle against this expression and reinforcement of patriarchy. More importantly, there is a need to influence institutional-level policy implementation on SGBV.

This requires moving beyond focusing on changing individual men's attitudes and behaviours and beginning purposefully to engage in tackling the sociocultural, economic and political institutions structuring men's lives. As gender inequalities, and the violence that sustains them, are upheld by different institutions, curbing institutional violence requires interrogating the structural and organisational measures put in place within different institutions. This includes policies, which may refer neither to the significance of gender equality (and the role men have to play in its promotion), nor to institutional practices, such as the extent of support or lack of it for such awareness by staff and especially senior management. A fundamental issue in this regard has been the significance of working with policymakers within institutions to increase the focus on and understanding of gender equality issues within their institutions.

According to the Kenya Demographic Health Survey (KDHS) 2008/09, 43 per cent of 15-49year-old women reported having experienced some form of SGBV in their lifetime, with 29 per cent reporting an experience in the previous year, 16 per cent of women reported having ever been 
sexually abused, and for 13 per cent, this had happened in the last year (Kenya National Bureau of Statistics (KNBS) and ICF Macro 2010). While women and men, girls and boys face a range of vulnerabilities to violence throughout their lives, around the world women and girls suffer specific types of violence disproportionately because of their gender. In sub-Saharan Africa, being born female can result in exposure to female infanticide, differential access to food and healthcare, child marriage, female genital mutilation, bride price abuse, and sexual violence and exploitation. All of these forms of SGBV expose women and girls to a variety of negative physical and emotional health outcomes, and limit their opportunities to contribute to, and benefit from, development. The low status of women relative to men and the low value accorded to them is the root cause of SGBV. In most societies there are systematic efforts to rationalise, justify and explain SGBV as part of culture, religion or the consequence of stressful lifestyles.

Acts of SGBV have commonly been grouped into five categories: sexual, physical, emotional and psychological, harmful traditional practices (sometimes referred to as sociocultural violence) and socioeconomic. However, these categories are neither exhaustive nor exclusive since they do not include other forms of violence that also violate human rights. Institutional SGBV is a pressing problem not only because it is deeply rooted within institutional structures and is correspondingly difficult to unravel, but also because it violates human rights and poses a challenge to public health, economic and social development. International development bodies have only seriously begun to acknowledge it in the past decade, as stressed by the UN SecretaryGeneral, Kofi Annan, at the Beijing + 10 meeting in New York, in March 2005:

Sixty years have passed since the founders of the United Nations inscribed on the first page of our Charter the equal rights of women and men. Since then, study after study has taught us that there is no tool for development more effective than the empowerment of women. No other policy is as likely to raise economic productivity or to reduce infant and maternal mortality. No other policy is as sure to improve nutrition and promote health including the prevention of HIV/AIDS. No other policy is as powerful in increasing the chances of education for the next generation. And I would venture that no policy is more important in preventing conflict, or in achieving reconciliation after a conflict has ended (Annan 2005).

SGBV violates many fundamental rights protected by international human rights instruments, including the right to life and the right not to be subjected to torture or cruel, inhuman or degrading treatment, protected by the Universal Declaration of Human Rights (UDHR) and the Convention on the Elimination of all forms of Discrimination Against Women (CEDAW) among other conventions. To remove the threat of SGBV there must be programming that specifically confronts the institutional systems and environments that facilitate and enable SGBV to thrive. This means challenging those elements of male culture, which reinforce unbalanced power relations and prioritise men's physical, sexual and emotional desires above the rights of women.

In Kenya, as in many other parts of Africa and indeed the world, SGBV is a multidimensional issue caused by numerous factors in society. It is therefore imperative that approaches to curb SGBV are multifaceted. Despite the efforts being put in place by different actors, SGBV prevention and response mechanisms in Kenya are not yet institutionalised. The modest efforts made face innumerable impediments, which, if not dealt with, might lead to erosion of the gains already realised. Above all, there is a need to establish spaces for negotiation with duty-bearers within different institutions while at the same time empowering the rightsholders with lobbying and advocacy skills. This will ensure that the dutybearers are held accountable and heighten the formulation and implementation of policies and laws that are responsive and geared towards the realisation of social justice. Good progress has been made, particularly in the government ministries, where personnel are required to sign performance contracts with regards to gender mainstreaming in their different dockets. ${ }^{1}$

\section{Engaging men to combat institutional SGBV}

Men can be instrumental in ending SGBV, the spread of HIV and AIDS and changing cultural and institutionalised perceptions about violence since they frequently hold decision-making powers within various institutions. It is important 
to highlight men who are committed and passionate about gender equality and thus oppose gender relations that exploit and oppress women. This calibre of men also opposes and resists the exploitation and oppression of men by other men and they are committed to social change in the current global disorder. Men must rise up and condemn exclusivity in the perpetuation of the rights of all and guard against homophobic or male chauvinistic tendencies. As human rights and social justice activists, men should readily accept the leadership of women in all spheres of society. Organisations such as Men for Gender Equality Now (MEGEN) in Kenya, Promundo in Brazil and Sonke Gender Justice in South Africa, to mention a few, have been on the frontline of engaging and enlisting men as agents of change. The efforts of such groups have started bearing fruit as men have started to embrace discussions on gender issues, not as women's affairs but as essential elements of sustainable development. 'A vast majority of men are not violent, but are rather silent bystanders when it comes to violence that other men commit. This is worse than violence itself since violence thrives on our silence' (paraphrased from Ted Bunch, Co-Founder of a Call to Men).

In MEGEN's experience a lot of men have not considered that they have a role in confronting issues of violence, and most are totally ignorant of the consequences to themselves, women, girls, boys and society as a whole. In some communities, violent acts are encouraged and embraced as a normal way for a boy or man to affirm their manhood. In many cases, men and boys suffering from a change in gender roles, or those who fail to meet the sociocultural expectations of masculinity, express their frustrations through violence against women and girls. Such gender perceptions contribute to the expression of violent behaviour and the subsequent SGBV and disparity experienced mainly by women and girls.

\section{Initiatives of men who struggle for gender} equality should be recognised as important factors in the struggle against powerlessness. Consequently, the role of women's human rights and social justice movements in the establishment and fostering of some of these initiatives must be advanced within a principled dialogue between these groups. Prevention and response programmes must strive to support men to surmount the destructive effects of unyielding and stereotyped masculinities.

Simultaneously, men's patterns of personal and societal violence and abuse toward women, children and other men should be confronted. Men are restricted to limited and somewhat repressive roles under male dominance.

Men's engagement in gender equality initiatives and in combating SGBV remains an area of theoretical and practical inquiry. Such inquiry will be resisted by various vested interests, including men themselves. The danger is that such paradigms never engage with issues of power and diversity. It is therefore pertinent to interrogate how men deal with the issue of diversity in masculinities. Towards that end, there is a need to create spaces for negotiations with and involvement of men in sensitising other men, coupled with support from different sectors. Male inclusion in the gender mainstreaming process has increasingly been documented as vital to the success of mainstreaming efforts. It is well understood that the achievement of gender equality is not possible without the active involvement and support of men. Men must be reached and included so that male resistance does not derail interventions for women and girls.

The incorporation of boys and men into the struggle to end forms of institutional SGBV is complex, and often requires that they confront their own masculinity and the patriarchal order, and interrogate their own social identity. This requires attitudinal systems and behavioural change, especially on the part of men and boys, who continue to be the vast majority of perpetrators. Governments and social justice movements should strive to come up with programmes that assist men and boys as well as promote the growth of a community of men who are committed to cultural and institutional change.

There is also a need to address women's practical and strategic needs in terms of how women and men's productive lives are interdependent. Men must be engaged to enable them to take responsibility and be accountable - including training them to talk to their peers and never be silent bystanders whenever violence occurs. The government of Kenya has made tremendous strides in ensuring that women are given opportunities, including resources to address their 
strategic needs. With the recent launch of the UWEZO (Empowerment) fund, worth six billion Kenya shillings (US\$70 million), women can now access funds for start-up business ventures.

\section{Analysis of male privileges}

All men, although not homogenous, share one thing in common - male privilege. In most societies, males are granted preferential treatment by virtue of being born male. This gives them easy access to positions of influence, power, authority and preferential access to resources compared with women. Men enjoy these privileges and seldom pause to analyse the responsibilities and risks that come with the advantages they have over women. It is worth noting that the roles and choices men make as individuals inform and shape the manifestation of power in public spaces.

In most cultures, men and boys are socialised to be competitive, aggressive and dominant.

Political and economic power are valued and rewarded. Physically and financially powerful men are viewed as desirable by women and enviable by other men. Men are also sometimes socialised to be sexually promiscuous, even sexually irresponsible. Amongst themselves, men often brag about their sexual prowess - long a means of establishing status between men. The role of 'stud' has often been coveted and valued in many societies, by both men and women (Tucker-Ladd 1996).

Despite the male socialisation process, however, caution must be exercised in depicting women as being essentially peaceful and men as essentially violent. These depictions reinforce antiquated, patriarchal models of masculinity and femininity and negate patterns of dominance and violence practised by women, as well as patterns of peace and respect practised by both men and women. In fact, research has shown that on intellect, temperament and other personal traits, there are no measurable differences between men and women, and when differences do appear they are small in comparison to variations within each of the sexes.

Gultural forms of masculinities oftentimes use SGBV and other forms of violence as a means of instituting and sustaining power relationships and structural inequities and inequalities. Regrettably, culturally prevailing norms of masculinities that encourage men to use violence restrict men and women's choices, perceptions and attitudes towards each other. Due to male privilege, men always work hard to ensure that they maintain the status quo throughout their lifetime. Violence is therefore seen as a systematic way of enhancing male supremacy.

On the other hand, since men benefit from gender inequalities, it is ostensibly to their benefit to keep this privilege veiled from critical scrutiny. Fearing ridicule and derision by fellow men, most men thus feel pressured to conform to culturally sanctioned versions of masculinities. There may also be resistance by some women who see men who enter into gender discourse as intruders. Njoki Wainaina (a consultant with African Women's Development and Communication Network (FEMNET) and currently the National Gender Advisor - MEGEN) expresses her experience in working with men and boys as follows:

There are many women today who feel that working with men and boys is diluting, diverting and trivializing the struggle. Many hold the view that because men and boys are the beneficiaries of male privilege and discrimination against women and girls, they can never understand our struggle. Many doubt that men and boys can commit to changes that would mean them losing the privileges they now enjoy. But, as understandings of gender, its construction, masculinities, femininities and their impact on all deepen, it becomes clear that males have reasons to want to change as well and that gender equality would also benefit them. Work with men and boys for gender equality is only one of the many strategies that must be combined to tackle the ever-growing problems of inequality, injustice and oppression (Wainana 2004).

Violence escalates whenever men feel their masculinity is confronted. While factors such as poverty, alcohol and unemployment may be the context of violence, the difference in status between women and men is the root cause of violence. Men maintain, reproduce and sanction the majority of social structures that justify the subordination of women, promote unhealthy male behaviour and emasculate attempts by other men to become engaged in social justice initiatives. Boys, on the other hand, tend to emulate and embrace what adult males do. 
Therefore, it is critical that they are engaged in gender justice work at an early age before they acquire negative forms of masculinities. Due to their positions of influence and their decisionmaking powers in most communities with regard to economic, political and sociocultural resources (resources required to implement women's right to justice), men are thus influential in ending SGBV and changing cultural and institutionalised perceptions about violence.

\section{Bottlenecks to women's participation in politics}

In Kenya, affinity with the male-dominated political party leadership is critical for visibility and eventual nomination. During Kenya's March 2013 elections, no woman was elected governor or senator in any of the 47 counties, and only 16 were elected members of the National Assembly from all the 290 constituencies. This is despite the provisions of the Kenyan Constitution (2010), Article 81 Clause (b) which states that 'not more than two-thirds of the members of the elective public bodies shall be of the same gender'. Article 197 Clause (1) states, 'Not more than two-thirds of the members of any county assembly or county executive committee shall be of the same gender'. While the intentions are well-meaning, these two legislations could be used to lock out women from other spheres, notably the professional bodies, the executive, judiciary, and the administration including the civil service and parastatals. This means that in other spheres of life representation of women might remain below the one-third Constitutional requirement. It is therefore essential that these two Constitutional clauses are monitored closely and their implementation fast-tracked.

It is appalling that for one to be nominated or elected, they must be seen by their party to be 'sellable'. Several factors, such as consistency, financial standing, contribution to party work and affinity with the party leader, determine whether or not one is sellable. This means that a party will invest in a candidate if that candidate invests in it. Most political parties in Kenya are not institutionalised and are mainly patronageoriented in their structures, with authority based on traditional authority or charismatic leadership, rather than legal-rational authority. In a nutshell, parties have very low degrees of institutionalisation, making it difficult for outsiders to shuffle through (that is, find ways or spaces to articulate their concerns). Marginality of women in political party structures compounds their representation even more. Party ideologies, policies and standards are male-centred yet they are used to gauge women's performance in politics.

The underlying disparities are intricate and deeply entrenched patriarchal sociocultural, economic and political structures and ideologies are legitimised by an undemocratic system of governance. In light of this, women are excluded from participation in key leadership positions and end up enduring deprivation of basic human rights and ownership of strategic resources, which denies them the opportunity to participate on an equal footing with men in a democratic process.

\section{Factors that influence institutional violence}

There are myriad sociocultural factors that determine institutional violence (that is, power and control over resources, women empowerment factors, policy and institutional frameworks). Some of these factors are highlighted below:

- Policy and institutional framework: Leniency in, or lack of, prosecution of perpetrators of abuse against women, absence of or weak institutional frameworks, lack of proper and gender-responsive policies and legislation, as well as lack of political will to address the institutional inequities.

- Structural factors: Poverty, patriarchy, gender inequity and inequality, discrimination, exploitation, unequal power relations, lack of gender-responsive budgeting and facilities to address SGBV, corruption, and lack of proper mechanisms for enforcing laws.

- Social and cultural factors: Negative masculinities (including male privileges, injustices and impunity), negative customs and traditions, culture and religion, social acceptance of violence against women, negative socialisation, and ignorance of the rights of women.

- Women's disempowerment: Insufficient awareness creation and sensitisation on human rights including the rights of women and girls, power and control over women's bodies, low literacy levels amongst women, disengagement of women in gainful undertakings thus creating economic dependency.

- Resource-linked factors: Inequity in access and control of resources and opportunities, unfair division of labour, economic vulnerability, poverty, conflict and displacement. 
The above factors contribute greatly to the prevalent violations of women's and girls' rights, mainly within institutions. Nevertheless, turning these clusters (that is, structural, social and cultural factors) around exhibit strengths that, if tapped into and reinforced, would contribute immensely to the reduction of SGBV within different institutions. For example, if instead of negative masculinities (a social and cultural factor), we instil positive masculinities and highlight the cost of male privileges to men, boys and the society, then we can begin the process of societal transformation.

\section{Constraints to prevention of and response to institutional SGBV in Kenya}

The National Framework on Gender-Based Violence (GBV) Prevention and Response in Kenya developed in 2009 was seen as a progressive step towards a structured coordination of the multi-pronged efforts to prevent and respond to SGBV. However, there was a delay in finalising the development of the National Action Plan towards implementation of the Framework on GBV prevention and response. A proposed Monitoring Framework of the National Action Plan on Gender-Based Violence prevention and response, which would be essential for the multisectoral organisation, is still unavailable.

Lack of resources from the government kitty for SGBV programmes, along with shrinking donor funding, make the future of most programmes uncertain. It would seem that there is a lack of centralised and systematic data collection in Kenya, making it almost impossible to measure the impact that prevention and response initiatives are having, particularly on institutional forms of SGBV and on policymaking processes.

There is also a huge gap between policy, law and practice. Even where hard-won legislation is in place, such as the Sexual Offences Act 2006, implementation is poor. In the police service, understanding of human rights and appreciation of the nature of SGBV crimes are still wanting. Other challenges include violence and intimidation for challenging the hegemonic norms of patriarchy and heteronormativity. It is worth noting that there is an intersection between socioeconomic rights and the structural violence faced especially by women; human rights activists working to end these inequities and inequalities must therefore strive to address the connections.

\section{Promising interventions}

SGBV is one of the most topical issues of concern in the human rights discourse. In the last decade it has found its way into the policies, strategies and political agendas of many organisations. Creation of a coordinating system to consolidate gains and efforts should be geared towards adding to the national effort, avoiding unnecessary duplication and bridging identified gaps. The following strategies are some of the ways in which actors can engage with the communities to bring about the desired change in society.

- Rights awareness education;

- Strengthening legislation, institutional and policy frameworks and respect for the rule of law;

- Strengthening legal structures and frameworks to stop violence against women;

- Male engagement in initiatives geared towards curbing SGBV;

- Awareness-raising, enabling women and girls to demand justice and challenge violation of their rights;

- Availability and accessibility of best practices on human rights in Kenya and across the entire continent of Africa, and efforts of civil society organisations to advocate for laws and policies that support the promotion and protection of the rights of women and girls;

- Male engagement in initiatives to challenge institutionalised forms of violence;

- Gender equality issues should be entrenched within the school curricula with the aim of inculcating a culture of respect for women and girls.

\section{Constraints that impede the reporting of cases of SGBV}

In MEGEN's interactions with diverse communities in Kenya, the following are reasons given to explain why survivors of SGBV do not report the incidents.

- There is an overwhelming distrust of local authorities and the police by the local community, due to high levels of corruption, apathy and ignorance associated with them. Additionally, as the people are conservative they prefer to settle cases of SGBV, such as defilement and rape, within the community and without police or local authority involvement.

- Fear of stigmatisation impedes the reporting of SGBV cases due to a strong tendency in 
most institutions and communities to perceive survivors as somehow deserving of the abuse or as having encouraged it.

- Insensitive investigations of SGBV cases cause further psychological and sometimes even social injuries to the victims. The long and complex legal process makes it difficult for survivors to follow their case to its conclusion.

- In most police stations, the officers at the gender desks are not well prepared and are thus unaware of how to handle SGBV issues and what roles they are supposed to play in such cases. This greatly impedes the reporting of SGBV cases.

- As the perpetrators of violence hardly ever take responsibility for their actions and instead blame the survivors once they are arrested and subsequently sent to prison, fear of revenge by either the perpetrator or his friends or relatives discourages the reporting of SGBV cases.

- There is a lack of awareness at the community level of the laws and policies that protect people against SGBV, such as the Sexual Offences Act 2006. Most people are also not familiar with the specific procedures to follow in handling or reporting incidents.

- Local leaders are ignorant of their roles and duties in the community and of laws and policies on SGBV.

There is a significant relationship between awareness of SGBV policies and the tendency to report incidents. As might be expected, those unaware of the policy are less likely to report incidents. Thus, while general awareness is quite high, suggesting little effect on the gap between incidents and reports, it appears that reporting rates could be increased through continued awareness campaigns.

\section{The way forward}

It is essential to build on existing mandates, structures and programmes, thereby anchoring interventions on existing systems, be they legal, traditional, institutional or otherwise. Building of partnerships through a multisectoral approach involving all stakeholders, such as people at decision-making and policymaking levels, students, refugees, implementing partners (IPs), government and humanitarian aid providers cannot be gainsaid. It is imperative to customise messages for different audiences using multiple media sources. These messages must strive to target men and boys and teach them alternative constructs of masculinity. At the community level, it is important to engage people to conduct their own analysis in order to identify the root cause of SGBV within the context and institutions that perpetuate them.

\section{The Director of Public Prosecutions (DPP) in}

Kenya has since appointed special prosecutors to handle SGBV cases and to expedite the prosecution process. The next level should be a creation of special courts to address SGBV cases with defined guidelines and procedures. There still remains the expansion of the jurisdiction of existing courts, and establishing mobile courts to facilitate accessibility.

\section{Alliance-building and collaboration amongst actors on best practices and standards for curbing SGBV should be encouraged. Efforts to engage men and boys to nurture positive masculinities within the existing structures should be enhanced.}

Researchers have their work cut out - they need to improve data collection and analysis that can in turn inform programming. This should be coupled with sustained advocacy around SGBV as a watershed, including its intersections with development, governance, peace and security. To achieve this, development partners must be involved to provide realistic, long-term financial and technical support that facilitates sustainable home-grown interventions to prevent and respond to SGBV. Finally, it is important to be patient and sensitive in developing discussions with men and boys on issues of gender.

\section{Conclusion}

Gender inequality is a major cause of poverty in Kenya and women are still constrained in securing basic education, finding employment and having a fair degree of control over household income. Until gender discrimination is ended, through the promotion of gender equality, these issues cannot be successfully addressed. The patterns of domination, though, may be so deeply rooted in cultures and institutions that, if not carefully scrutinised, they may go unnoticed. Awareness, analysis and visibility are key starting points in the task of understanding gender roles and masculinities and their impact on programmes, services and initiatives working to address gender equality. 
There is a need to develop approaches and strategies for male inclusion in the gender equality process, including deepening the understanding of the resistance encountered, documenting what works and developing tools for

\section{Note}

1 Within the leadership structures, or rather ranks and files, in the different institutions.

\section{References}

Annan, K. (2005) Male Involvement in Promoting Gender Equality, www.wunrn.com/news/2006/ 01_08_06/010906_male_involvement.htm (accessed 14 November 2011)

KNBS and ICF Macro (2010) Kenya Demographic and Health Survey 2008-09, Galverton MD: Kenya National Bureau of Statistics and ICF field-based practice. It is important to stress that promoting gender equality is not about granting privileges to women while disempowering men. It is about creating a more socially just world by integrating approaches that benefit all.

Macro, www.measuredhs.com/pubs/pdf/ FR229/FR229.pdf (accessed 19 Nov 2013) Tucker-Ladd, C.E. (1996) 'Understanding Ourselves and Our Relationships', chapter 9 in Society Establishes Gender Roles for Men and Women, Psychological Self-Help: 701-829 Wainana, N. (2004) FEMNET Newes, (January/ April): 2 